\title{
Use and nonmedical use of prescription opioid analgesics in the general population of Canada and correlations with dispensing levels in 2009
}

\author{
Kevin D Shield $\mathrm{MHSC}^{1,2}$, Wayne Jones MSc MA ${ }^{3}$, Jürgen Rehm $\mathrm{PhD}^{1,2,4,5,6}$, Benedikt Fischer $\mathrm{PhD}^{1,3}$
}

\begin{abstract}
KD Shield, W Jones, J Rehm, B Fischer. Use and nonmedical use of prescription opioid analgesics in the general population of Canada and correlations with dispensing levels in 2009. Pain Res Manag 2013;18(2):69-74.
\end{abstract}

BACKGROUND: In Canada, harm from nonmedical prescription opioid analgesic (POA) use (NMPOU) has increased in recent years; however, there are limitations to the current estimates of NMPOU. The 2009 Canadian Alcohol and Drug Use Monitoring Survey presents an opportunity to produce more accurate estimates of NMPOU.

OBJECTIVES: To determine the prevalence of POA use, NMPOU and use of pain relievers to 'get high', and to assess correlations of these indicators with age, sex and provincial levels of dispensed POAs in Canada in 2009.

METHODS: Data regarding POA use were obtained from the 2009 Canadian Alcohol and Drug Use Monitoring Survey $(n=13,032)$. The amount of POAs dispensed in standardized daily doses was obtained from a representative sample of 2700 retail pharmacies across Canada. Associations among POA use, age, sex and the amount of POAs dispensed were evaluated using regression models. Differences in POA use across provinces were assessed using the Wald test.

RESULTS: In Canada in 2009, the prevalence of POA use was $19.2 \%$ (95\% CI $18.0 \%$ to $20.5 \%$ ), NMPOU was $4.8 \%$ (95\% CI $4.1 \%$ to $5.5 \%$ ) and the use of pain relievers to get high was $0.4 \%$ (95\% CI $0.1 \%$ to $0.8 \%$ ). NMPOU was significantly associated with age. The use of pain relievers to get high varied significantly across provinces, while POA use and NMPOU did not show significant variations. The amount of POAs dispensed per province was not significantly correlated with any type of POA use.

CONCLUSIONS: These findings confirm high POA use and NMPOU across Canada. Research is required to identify determinants of NMPOU.

Key Words: Canada; General population surveys; Pain care; Prescription opioids; Substance abuse

\author{
L'utilisation d'analgésiques opiacés à usage médical \\ et non médical dans l'ensemble de la population du \\ Canada et les corrélations avec les taux \\ d'administration en 2009
}

\begin{abstract}
HISTORIQUE : Au Canada, les dommages causés par l'utilisation d'analgésiques opiacés d'ordonnance $(\mathrm{AOP})$ à des fins non médicales (UOONM) ont augmenté ces dernières années, mais les évaluations actuelles de l'UOONM comportent des limites. L'Enquête de surveillance canadienne de la consommation d'alcool et de drogues de 2009 constitue une occasion d'évaluer l'UOONM avec plus d'exactitude.
\end{abstract}

OBJECTIFS : Déterminer la prévalence d'utilisation d'AOP, l'UOONM et l'utilisation d'analgésiques pour se droguer et évaluer les corrélations de ces indicateurs avec l'âge, le sexe et le taux provincial d'administration d'AOP au Canada en 2009.

MÉTHODOLOGIE : Les données relatives à l'utilisation d'AOP sont tirées de l'Enquête de surveillance canadienne de la consommation d'alcool et de drogues de 2009 ( $\mathrm{n}=13$ 032). La quantité d'AOP administrés à des doses quotidiennes standards est extrapolée d'un échantillon représentatif de 2700 pharmacies de détail au Canada. Les chercheurs ont évalué les associations entre l'utilisation d'AOP, l'âge, le sexe et la quantité d'AOP administrés au moyen de modèles de régression. Ils ont évalué les différences d'utilisation d'AOP entre les provinces à l'aide du test de Wald.

RÉSULTATS : Au Canada en 2009, la prévalence d'utilisation d'AOP s'élevait à 19,2 \% (95\% IC 18,0\% à 20,5\%), d'UOONM, à 4,8\% (95\% IC 4,1\% à 5,5\%) et l'utilisation d'analgésiques pour se droguer, à $0,4 \%(95 \%$ IC 0,1 \% à 0,8\%). L'UOONM s'associait de manière significative à l'âge. L'utilisation d'analgésiques pour se droguer variait considérablement entre les provinces, tandis que l'utilisation d'AOP et l'UOONM n'affichaient pas de variations significatives. La quantité d'AOP administrés n'était corrélée de manière significative avec aucun type d'AOP utilisé.

CONCLUSIONS : Ces observations confirment l'utilisation élevée d'AOO et l'UOONM au Canada. Des recherches s'imposent pour établir les déterminants de l'UOONM.

Prescription opioid analgesics (POAs) are important medications
for the treatment of acute, severe and chronic pain (eg, pain
caused by cancer) (1-3). However, the use of POAs in the treatment
of chronic pain unrelated to cancer is controversial because this
treatment is associated with a higher risk of mortality and morbidity
related to POA use and nonmedical POA use (NMPOU) (4). In
recent years, NMPOU and POA-related morbidity and mortality
have emerged as major public health challenges, primarily in North
America (5-7). For example, it has been documented that in the
United States (US) in 2009, approximately $4.9 \%$ of the general
population had engaged in NMPOU in the previous year (8). In the
US in 2008, there were approximately 14,800 POA-related acci-
dental deaths, and a substantive increase in POA-related emergency
room and substance use treatment admissions has been observed (9). In 2006, the estimated cost of NMPOU in the US was $\$ 53.4$ billion (10). Although NMPOU is primarily an issue in North America, it is increasingly recognized as a problem in other areas, including Australia (past-year prevalence of NMPOU of 2.5\% [11]) and other countries (12)

In Canada, there are indications of POA-related problems similar to those found in the US; however, data are significantly more limited and fragmented (ie, restricted to select provincial indicators). Most available Canadian data are from Ontario, where recent studies have indicated high levels of NMPOU among both the general adult population and among high-school students, as well as increases in POA-related treatment admissions and deaths (7,13-15); however, most of these data are not available for all of Canada.

${ }^{1}$ Centre for Addiction and Mental Health; ${ }^{2}$ Institute of Medical Science, University of Toronto, Toronto, Ontario; ${ }^{3}$ Centre for Applied Research in Mental Health and Addiction, Faculty of Health Sciences, Simon Fraser University, Vancouver, British Columbia; ${ }^{4}$ Dalla Lana School of

Public Health, University of Toronto, Toronto, Ontario; ${ }^{5}$ Institute for Clinical Psychology and Psychotherapy, TU Dresden, Dresden,

Germany; ${ }^{6}$ Department of Psychiatry, University of Toronto, Toronto, Ontario

Correspondence: $\mathrm{Mr}$ Kevin D Shield, Centre for Addiction and Mental Health, 33 Russell Street, Toronto, Ontario M5S 2S1.

Telephone 647-971-6175, fax 416-260-4146, e-mail kevin.shield@utoronto.ca 
A rare and important opportunity to assess, and compare among provinces, Canada-wide data of POA-related indicators - specifically, self-reported POA use as well as measures of NMPOU and use of pain relievers to get high - is provided by the 2009 iteration of the Canadian Alcohol and Drug Use Monitoring Survey (CADUMS), which collected information on sources of POA for all individuals who used POA in the previous 12 months (16). Previous iterations of the CADUMS and the 2010 iteration of the CADUMS did not collect this information from participants. The prevalence of POA use and NMPOU are of interest because emerging literature presents consistent evidence that levels of POA use are significantly associated with levels of POA-related problems. Specifically, correlations between POA use and NMPOU, POA-related emergency room admissions, substance use treatment admissions and mortality levels have been found over time at a population level for various jurisdictions in the US and Canada (17-19). Given that recent analyses for the period between 2005 and 2010 have documented substantial differences in POA dispensing across Canadian provinces - with a total range of up to 2.5 -fold differences in standardized volumes - an examination of possible links between the amount of POAs dispensed and the prevalence of POA use or NMPOU is warranted, especially given that similar state-level analyses are not available for the US $(20,21)$.

On this basis, the main objectives of the present study were to document indicators for any POA use, NMPOU and use of pain relievers to get high for Canada and each province as reported by the CADUMS; and to assess correlations of these indicators with age, sex and provincial levels of dispensed POAs.

\section{METHODS}

Estimates of the prevalence of any POA use, NMPOU and the use of pain relievers to get high were calculated using data from the 2009 iteration of the CADUMS (CADUMS 2009) (22); the exact methods of the CADUMS 2009 are presented elsewhere (16). The CADUMS 2009 was used because it included more questions regarding NMPOU than other versions, allowing for a more accurate calculation of NMPOU (23). The CADUMS 2009 was representative for Canada, and used a provincially stratified two-stage (telephone household, respondent) probability sampling (using random digit dialing methods and computer-assisted telephone interviewing) performed in 11 waves between January 2009 and November 2009. Within each household, respondents who were 15 years of age or older were eligible to complete the survey in either English or French. Overall, 13,082 individuals participated in the survey, resulting in an effective overall response rate of $44.68 \%$ (calculated according to a previous study [24]).

NMPOU was defined as answering 'yes' to any of the following questions: "Sometimes people do not take their pills as directed by a physician or pharmacist. Thinking about ALL the pain relievers you have used during the past 12 months, did you ever take more pills, more often or for a longer period of time than you were supposed to?"; "During the past 12 months, did you ever use pain relievers to get high?"; or answering yes to obtaining prescription opioids "from a pharmacist, without a prescription?", "from a prescription written for someone else such as a family member or a friend?", "from someone else, without a prescription?", "from the Internet?", and/or "from any other source?" (not including a prescription written for the POA user). The use of pain relievers to get high was defined as answering "yes" to the question: "During the past 12 months, did you ever use pain relievers to get high?" A total of 13,023 participants answered all questions pertaining to the use of POAs, forming the base sample for analyses in the present study. Analyses for the prevalence of POA use according to age and the association of POA use and age excluded an additional 48 participants for whom age was not available.

The different types of POAs dispensed based on outpatient prescriptions in Canada in 2009 were calculated using data from
IMS Brogan's representative survey of 2700 retail pharmacies across Canada (21). POA dispensing rates were indicated using standardized defined daily doses (DDD) according to standards and methodology defined by the WHO (25). Because the prescribing data were not disaggregated according to sociodemographic information, no subpopulation level (according to province) analysis was possible. Prescribed POAs were further disaggregated based on the WHO's pain ladder, with codeine and its combination products defined as 'weak opioids' and hydrocodone, hydromorphone, oxycodone, fentanyl, meperidine, methadone and morphine defined as 'strong opioids'.

Tests of association among POA use, NMPOU and the use of pain relievers to get high, and the amount of POAs and strong POAs prescribed were performed using general linear models (with a logit distribution family function and an exponential link) that accounted for the design of the CADUMS 2009. Differences across provinces among POA use, NMPOU and the use of pain relievers to get high were tested using an adjusted Wald test for survey data (26). A significant association was defined using an $\alpha$ of 0.05 . All statistical analyses were performed using $\mathrm{R}$ version 2.14.1 (27).

\section{RESULTS}

The prevalence of any POA use, NMPOU and the use of pain relievers to get high according to age and sex is outlined in Table 1 . In Canada in $2009,19.2 \%$ (95\% CI $18.0 \%$ to $20.5 \%$ ) of the study population used POAs (18.3\% [95\% CI $16.4 \%$ to $20.1 \%$ ] for men; $20.2 \%$ [95\% CI $18.5 \%$ to $21.8 \%$ ] for women); $4.8 \%$ (95\% CI $4.1 \%$ to $5.5 \%$ ) engaged in NMPOU (4.5\% [95\% CI 3.5\% to 5.5\%] for men; $5.1 \%$ [95\% CI $4.1 \%$ to $6.1 \%$ ] for women); and $0.4 \%$ (95\% CI $0.1 \%$ to $0.8 \%)$ used pain relievers to get high $(0.5 \%$ [95\% CI $0.0 \%$ to $1.0 \%$ ] for men; $0.4 \%$ [ $95 \%$ CI $0.0 \%$ to $0.7 \%$ ] for women) in the previous 12 months. Any POA use, NMPOU and the use of pain relievers to get high did not significantly differ according to sex. Any POA use did not significantly differ according to age; however, NMPOU significantly differed according to age $(\mathrm{P}=0.040)$ and significantly differed according to age when controlling for sex $(\mathrm{P}=0.038)$. Older individuals were significantly less likely to indicate that they had engaged in NMPOU. The use of pain relievers to get high did not exhibit any difference according to age.

The amount of POAs dispensed, in standardized DDD, and the prevalence of any POA use, NMPOU and the use of pain relievers to get high, for Canada and according to province, are outlined in Figure 1 (the prevalence of POA use, NMPOU and using pain relievers to get high according to sex and province are presented in Appendix 1).

Any POA use varied by province, from $16.3 \%$ (95\% CI $13.7 \%$ to $18.8 \%$ ) in Prince Edward Island to $20.4 \%$ (95\% CI $17.7 \%$ to $23.2 \%$ ) in Alberta. The prevalence of NMPOU was lowest in New Brunswick (2.8\% [95\% CI $1.7 \%$ to $4.0 \%]$ ]) and highest in Saskatchewan $(5.3 \%$ [95\% CI 3.8\% to 6.8\%]). No respondents in Alberta or Manitoba indicated the use of pain relievers to get high, whereas $0.9 \%(95 \% \mathrm{CI}$ $0.1 \%$ to $1.6 \%$ ) of respondents from Prince Edward Island indicated such use during the study period. Adjusted Wald tests for POA use across provinces approached significance $(P=0.068)$, while the adjusted Wald test was significant for differences in use of pain relievers to get high across provinces $(\mathrm{P}>0.001)$. There was no significant difference in NMPOU across provinces ( $\mathrm{P}=0.681$ ).

All associations between the amount of POAs dispensed and strong POAs dispensed, and the prevalence of any POA use, NMPOU and the use of pain relievers to get high were not significant. All regressions had a correlation coefficient ( $r$ ) of $<0.1$, except for the total number of strong POAs used and use of pain relievers to get high $(\mathrm{r}=0.54)$.

\section{DISCUSSION}

The present study examined indicators of POA use and NMPOU in the Canadian general population across provinces on the basis of national survey data and assessed correlations of these measures with provincial POA dispensing levels. 
TABLE 1

Use of prescription opioid analgesics according to age and sex in Canada in 2009

\begin{tabular}{|c|c|c|c|}
\hline Age group, years & Men & Women & Total \\
\hline \multicolumn{4}{|c|}{ Use of prescription opioid analgesics } \\
\hline $18-24$ & $14.7(8.4-20.9)$ & $14.7(9.0-20.5)$ & $14.7(10.5-18.9)$ \\
\hline $35-44$ & $18.1(13.9-22.3)$ & $18.8(15.2-22.5)$ & $18.5(15.7-21.2)$ \\
\hline $45-54$ & $18.9(15.2-22.5)$ & $24.2(20.4-28.1)$ & $21.6(18.9-24.3)$ \\
\hline $55-64$ & $23.2(18.6-27.7)$ & $24.7(20.9-28.6)$ & $24.0(21.0-26.9)$ \\
\hline \multicolumn{4}{|c|}{ Nonmedical prescription opioid analgesic use } \\
\hline $15-17$ & $6.1(0.0-12.3)$ & $7.2(0.0-15.3)$ & $6.6(1.5-11.6)$ \\
\hline $18-24$ & $4.5(0.9-8.2)$ & $3.9(0.6-7.1)$ & $4.2(1.8-6.6)$ \\
\hline $25-34$ & $5.6(2.1-9.1)$ & $7.2(3.6-10.9)$ & $6.4(3.9-8.9)$ \\
\hline $35-44$ & $4.4(2.1-6.6)$ & $5.1(2.9-7.3)$ & $4.7(3.2-6.3)$ \\
\hline \multicolumn{4}{|c|}{ Use of pain relievers to get high } \\
\hline $15-17$ & $2.8(0.0-7.9)$ & $0.5(0.0-1.1)$ & $1.7(0.0-4.6)$ \\
\hline $18-24$ & $0.2(0.0-0.5)$ & $1.8(0.0-4.2)$ & $1.0(0.0-2.2)$ \\
\hline $25-34$ & $1.8(0.0-4.6)$ & $0.7(0.0-1.9)$ & $1.2(0.0-2.7)$ \\
\hline $35-44$ & $0.1(0.0-0.3)$ & $0.2(0.0-0.5)$ & $0.2(0.0-0.3)$ \\
\hline $45-54$ & $0.1(0.0-0.3)$ & $0.0(0.0-0.0)$ & $0.1(0.0-0.1)$ \\
\hline $55-64$ & $0.0(0.0-0.0)$ & $0.0(0.0-0.0)$ & $0.0(0.0-0.0)$ \\
\hline$\geq 65$ & $0.0(0.0-0.1)$ & $0.0(0.0-0.0)$ & $0.0(0.0-0.0)$ \\
\hline Total & $0.5(0.0-1.0)$ & $0.4(0.0-0.7)$ & $0.4(0.1-0.8)$ \\
\hline
\end{tabular}

Data presented as \% (95\% Cl)

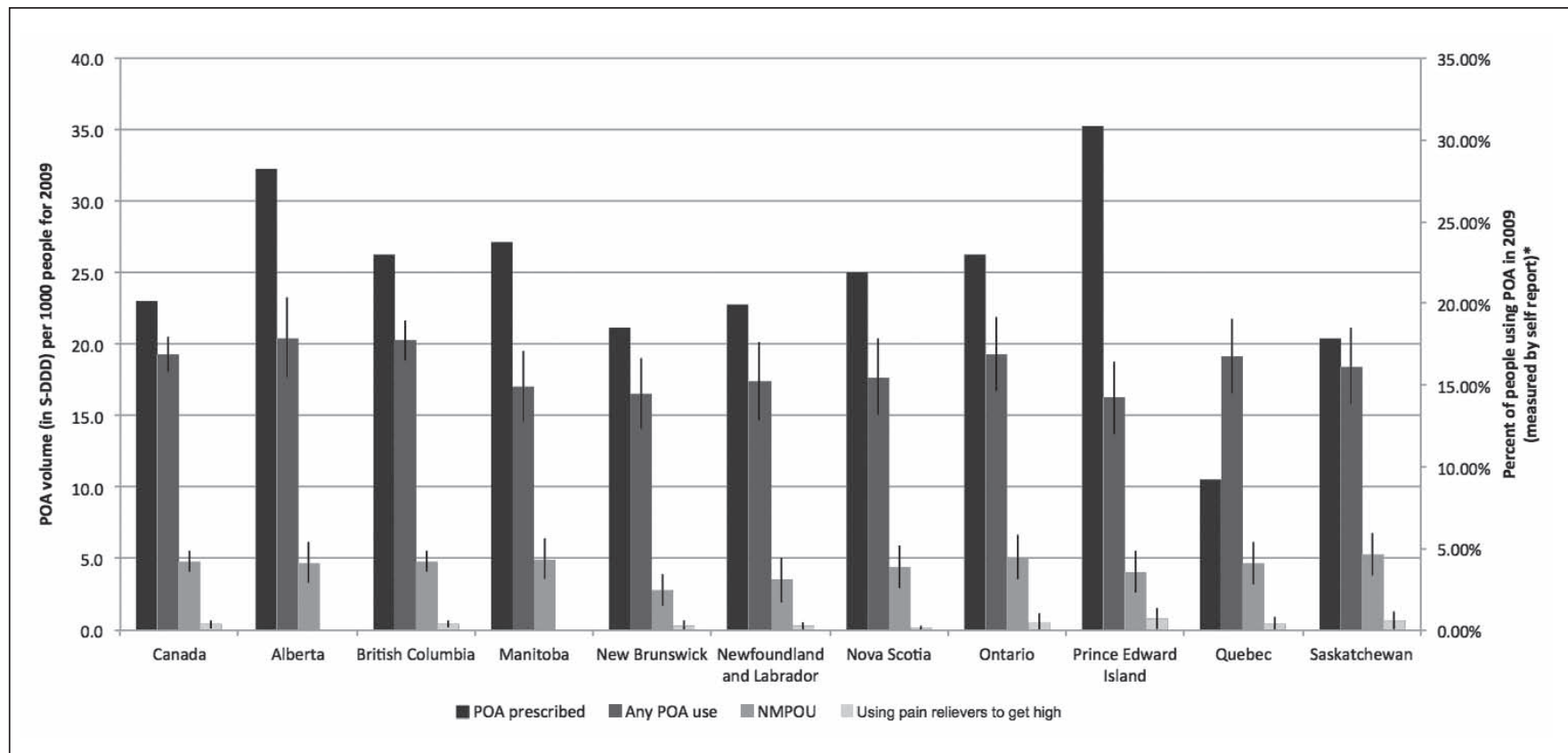

Figure 1) Amount of prescription opioid analgesics (POAs) dispensed and the prevalence of the use of POAs according to province in Canada in 2009. NMPOU Nonmedical POA use

CADUMS 2009 data confirm that POA use is common in the Canadian population; one in five adults used a POA in the previous year in 2009. These indicators are important because Canada has the secondhighest POA use among highly developed nations (for comparison, from 2008 to 2010, Canada reported use of 2.08, 2.56 and 22.72 times the DDD of POAs per one million inhabitants as did each of Australia, the United Kingdom and Japan, respectively, during the same period) (28). POA use presents a major public health problem in Canada and is associated with a substantial burden of mortality (14). The use of POAs in Canada is particularly alarming because it has tripled in the past decade alone $(7,28)$. 
The NMPOU prevalence estimate of approximately $4.8 \%$ for Canada is consistent with recently reported NMPOU prevalence estimates for both the Ontario and US general populations (15), thus confirming estimates that approximately one in 20 adults engaged in NMPOU. Given recent insights into the link between the prevalence of POA use and the prevalence of NMPOU, the similarity between the CADUMS 2009 and US prevalence estimates may appear unlikely because POA volume levels in the US are double those of Canada $(21,28)$. Furthermore, CADUMS 2009 data confirm that, in 2009, NMPOU was equally prevalent across virtually all age groups - including minors and adolescents - defying the common age patterns observed for other forms of drug use (eg, risky alcohol or cannabis use); however, the data do not confirm sex differences in NMPOU that have been observed in other surveys (29. 32).

In Canada in 2007 and 2008, approximately $18.5 \%$ of the population (12 years of age and older) experienced chronic pain (approximately four times the prevalence of NMPOU in Canada for 2009) (33). Thus, the proper treatment of chronic pain is of paramount importance $(3,34,35)$. To decrease the prevalence of NMPOU and its resulting harms, medical practitioners in Canada and the US should implement guidelines for POA treatment of chronic pain unrelated to cancer (36-38). However, data from the US suggest that the potential effects of these guidelines are limited because an estimated $40 \%$ of deaths from POA overdose occur in POA users that are prescribed POAs at high doses that are not within recommended guidelines (10\% of patients using POAs), 20\% of POA overdose mortality occurs from $\mathrm{POAs}$ prescribed within the recommended guidelines ( $80 \%$ of patients using POAs) and $40 \%$ of POA overdose mortality occurs in individuals who visit more than one medical practitioner to obtain POAs (10\% of patients using POAs) (4).

Data regarding the use of pain relievers to get high provide important insights. This form of NMPOU was reported by $0.4 \%$ of respondents (ie, $<10 \%$ of the rate reporting NMPOU). This discrepancy implies that the vast majority of individuals engaging in NMPOU did not perceive the use of POAs to be primarily for intoxication purposes. These findings may underscore the importance of survey item optimization, as well as the need to systematically examine motives, scenarios and practices of NMPOU to better understand NMPOU and to formulate targeted interventions $(15,39,40)$.

Our investigations did not find evidence of correlations between differential POA dispensing levels and the various self-reported indicators of POA use and NMPOU according to province (except for total POAs dispensed and use of pain relievers to get high, which had an $r$ of 0.54 ). This 'nonfinding' is surprising because a correlation of $r>0.1$ would intuitively be expected for the total amount of POAs dispensed and the prevalence of POA use and NMPOU; however, this nonfinding may be due to the small sample size (10 data points) used to estimate the correlation, or to confounding variables. Nevertheless, recent data from both the US and Canada have documented associations among POA use, NMPOU, POA-related morbidity (eg, ER and treatment admissions) and POA-related mortality rates in several different contexts (17-19). The volume of POAs dispensed does not necessarily translate into a predictably patterned distribution of POA use or NMPOU prevalence in the population. However, given the stark differences in levels of POA use among Canadian provinces, the prevalence of any POA use may be associated with the amount of POAs dispensed because, at a population level, it has been demonstrated that levels of POA-related mortality are markedly associated with high levels of POA use or dispensing (41-43). The finding of a nonsignificant correlation between POAs dispensed, and POA use and NMPOU may be correct in that these variables are not correlated. Further in-depth investigation of the significance of the correlation between POAs dispensed and POA use is warranted, given that an understanding of POA use is necessary for effective preventive interventions.
The present study was limited by the survey design and by the measurement of NMPOU. Measuring POA use, NMPOU and use of pain relievers to get high by means of a telephone survey design will generally lead to an undercoverage of these measures (44-46). In addition, the estimated prevalence of NMPOU has been shown to be associated with the questions asked to measure $\operatorname{NMPOU}(13,15)$. The CADUMS 2009 included questions relating to where POAs were acquired, which were asked of all participants who indicated POA use; such questions were not asked of all such participants in the 2008 iteration of the CADUMS $(16,22)$ and, thus, the CADUMS 2009 presents an opportunity to more accurately estimate NMPOU in Canada. However, the questions used to measure NMPOU in the CADUMS 2009 were not standardized. Given that nearly $5 \%$ of survey respondents acknowledged some form of NMPOU, it is important to further systematically develop, validate and standardize NMPOU items for future general population surveys (40). It is also important to determine whether individuals are using these medications because they are in pain, and what has led individuals who engage in NMPOU and were prescribed POAs to use them at higher doses and/or longer than was prescribed.

Our study was also limited by the small sample size available for analysis in the CADUMS 2009, evidenced by the fact that prevalence estimates of using pain relievers to get high were $0 \%$ in some provinces despite a sample size of more than 1000 adults. Because the behaviours of NMPOU and using pain relievers to get high in the general population are rare, a greater sample size is needed to determine whether there is a significant difference between NMPOU and the use of pain relievers to get high across provinces and to obtain accurate prevalence estimates. The variation in the amount of POAs dispensed limits our analysis because only the estimates of the amount of POAs dispensed in 10 provinces for a specific time period were available, rather than over multiple time periods. In addition, the tests of association between the amounts of POAs dispensed per province may have been affected by confounding variables that were not controlled for.

The data from the CADUMS 2009 suggest that an estimated $19.2 \%$ of Canadian adults used POAs in 2009 , an estimated $4.8 \%$ of Canadian adults admitted to having used POAs nonmedically and $0.4 \%$ of Canadian adults admitted to using pain relievers to get high. There was no significant association between POA use, NMPOU, and the use of pain relievers to get high and POA dispensing levels. These findings suggest high POA use and NMPOU across Canada; however, research is required to identify determinants of NMPOU.

\section{SUMMARY}

Using data from the 2009 CADUMS and 2700 pharmacies, the present study examined the prevalence of use of various types of POAs and the correlation among age, sex, amount of POAs dispensed in each province, and POA use and NMPOU. In 2009, $19.2 \%$ of Canadians used POAs, $4.8 \%$ engaged in NMPOU and $0.4 \%$ used pain relievers to get high. NMPOU was associated with age. Use of pain relievers to get high varied across provinces. All other associations were nonsignificant. These findings confirmed high levels of POA use and NMPOU across Canada.

CONFLICTS OF INTERESTS: The authors have no conflicts of interest to declare.

ACKNOWLEDGEMENTS: BF received salary support from a CIHR/ PHAC Chair in Applied Public Health. BF and JR received research support from CIHR grants SAF 94814 and GIR 109852, as well as salary and infrastructure support from the Ontario Ministry of Health and Long-Term Care. 
APPENDIX 1

Prescription opioid analgesic use in Canada in 2009 according to sex and province

\begin{tabular}{|c|c|c|c|}
\hline & Men & Women & Total \\
\hline \multicolumn{4}{|l|}{ Prescription opioid analgesic use } \\
\hline Alberta & $18.7(14.7-22.7)$ & $22.2(18.4-26.0)$ & $20.4(17.7-23.2)$ \\
\hline Manitoba & $15.6(11.8-19.5)$ & $18.3(15.0-21.7)$ & $17.0(14.5-19.6)$ \\
\hline New Brunswick & $16.1(12.3-19.9)$ & $16.9(13.6-20.2)$ & $16.5(14.0-19.0)$ \\
\hline Newfoundland and Labrador & $16.5(12.0-21.0)$ & $18.2(15.0-21.5)$ & $17.4(14.6-20.2)$ \\
\hline Prince Edward Island & $16.9(12.9-20.9)$ & $15.6(12.4-18.9)$ & $16.3(13.7-18.8)$ \\
\hline Quebec & $19.4(15.3-23.5)$ & $18.9(15.5-22.3)$ & $19.2(16.5-21.8)$ \\
\hline Saskatchewan & $18.2(14.2-22.3)$ & $18.7(15.3-22.1)$ & $18.5(15.8-21.8)$ \\
\hline \multicolumn{4}{|c|}{ Nonmedical prescription opioid analgesic use } \\
\hline Canada & $4.5(3.5-5.5)$ & $5.1(4.1-6.1)$ & $4.8(4.1-5.5)$ \\
\hline Alberta & $5.0(2.8-7.2)$ & $4.4(2.6-6.3)$ & $4.7(3.3-6.1)$ \\
\hline Nova Scotia & $5.2(2.8-7.6)$ & $3.8(1.9-5.7)$ & $4.5(2.9-6.0)$ \\
\hline Ontario & $4.3(2.2-6.4)$ & $5.8(3.5-8.1)$ & $5.1(3.5-6.6)$ \\
\hline Prince Edward Island & $5.4(2.8-7.9)$ & $2.9(1.4-4.4)$ & $4.1(2.6-5.5)$ \\
\hline Quebec & $4.2(2.0-6.5)$ & $5.1(3.1-7.1)$ & $4.7(3.2-6.2)$ \\
\hline Saskatchewan & $5.7(3.3-8.1)$ & $4.9(3.1-6.8)$ & $5.3(3.8-6.8)$ \\
\hline \multicolumn{4}{|c|}{ Use of prescription opioids to 'get high' } \\
\hline Canada & $0.5(0.0-1.0)$ & $0.4(0.0-0.7)$ & $0.4(0.1-0.8)$ \\
\hline Alberta & $0.0(0.0-0.0)$ & $0.0(0.0-0.0)$ & $0.0(0.0-0.0)$ \\
\hline British Columbia & $0.8(0.3-1.2)$ & $0.1(0.0-0.3)$ & $0.4(0.2-0.7)$ \\
\hline Manitoba & $0.0(0.0-0.0)$ & $0.0(0.0-0.0)$ & $0.0(0.0-0.0)$ \\
\hline New Brunswick & $0.5(0.0-1.4)$ & $0.2(0.0-0.6)$ & $0.3(0.0-0.8)$ \\
\hline Newfoundland and Labrador & $0.0(0.0-0.0)$ & $0.5(0.0-1.5)$ & $0.3(0.0-0.8)$ \\
\hline
\end{tabular}

Data presented as \% (95\% Cl)

\section{REFERENCES}

1. Ballantyne JC, Shin NS. Efficacy of opioids for chronic pain: A review of the evidence. Clin J Pain 2008;24:469-78.

2. Gardner-Nix J. Principles of opioid use in chronic noncancer pain. CMAJ 2003;169:38-43.

3. Kahan M, Mailis-Gagnon A, Wilson L, Srivastava A; National Opioid Use Guideline Group. Canadian guideline for safe and effective use of opioids for chronic noncancer pain: Clinical summary for family physicians. Part 1: General population. Can Fam Physician 2011;57:1257-66.

4. Manchikanti L, Abdi S, Atluri S, et al; American Society of Interventional Pain Physicians. American Society of Interventional Pain Physicians (ASIPP) guidelines for responsible opioid prescribing in chronic non-cancer pain: Part I - evidence assessment. Pain Physician 2012;15:S1-S65.

5. Manchikanti L, Helm S 2nd, Fellows B, et al. Opioid epidemic in the United States. Pain Physician 2012;15:ES67-ES92.

6. Volkow ND, McLellan TA. Curtailing diversion and abuse of opioid analgesics without jeopardizing pain treatment. JAMA 2011;305:346-7.

7. Fischer B, Argento E. Prescription opioid related misuse, harms, diversion and interventions in Canada: A review. Pain Physician 2012;15:ES191-ES203.

8. Substance Abuse Mental Health Services Administration. Results from the 2009 National Survey on Drug Use and Health: Volume I. Summary of National Findings. Rockville, Maryland: Substance Abuse and Mental Health Services Administration Office of Applied Studies, 2010.
9. Centers for Disease Control Prevention. Vital Signs: Overdoses of prescription opioid pain relievers - United States, 1999-2008. MMWR Morb Mortal Wkly Rep 2011;60:1487-92.

10. Hansen RN, Oster G, Edelsberg J, Woody GE, Sullivan SD. Economic costs of nonmedical use of prescription opioids. Clin J Pain 2011;27:194-202.

11. National Survey on Drug Use and Health. Trends in Non-medical use of Prescription Pain Relievers: 2002 to 2007. Canberra, Australia: The Australian Institute of Health and Welfare, 2008.

12. United Nations Office on Drugs and Crime. World Drug Report. Vienna, Austria: United Nations Office on Drugs and Crime, 2011.

13. Fischer B, Nakamura N, Ialomiteanu A, Boak A, Rehm J. Assessing the prevalence of non-medical prescription opioid use in the general Canadian population: Methodological issues and questions. Can J Psychiatry 2010;55:606-9.

14. Dhalla IA, Mamdani MM, Sivilotte ML, Kopp A, Qureshi O, Juurlink DN. Prescribing of opioid analgesics and related mortality before and after the introduction of long-acting oxycodone. CMAJ 2009;181:891-6.

15. Shield KD, Ialomiteanu A, Fischer B, Mann RE, Rehm J. Nonmedical use of prescription opioids among Ontario adults: Data from the 2008/2009 CAMH Monitor. Can J Public Health 2011;102:330-5.

16. Health Canada. Canadian Alcohol and Drug Use Monitoring Survey 2009: Microdata user guide. Ottawa, Canada: Health Canada, 2010.

17. Fischer B, Nakamura N, Urbanoski K, Rush B, Rehm J. Correlations between population levels of prescription opioid use and 
prescription-opioid-related substance use treatment admissions in the USA and Canada since 2001. Public Health 2012;126:749-51.

18. Wisniewski AM, Purdy CH, Bondell RD. The epidemiologic association between opioid prescribing, non-medical use, and emergency department visits. J Addict Dis 2008;27:1-11.

19. Dasgupta N, Kramer ED, Zalman MA, et al. Association between non-medical and prescriptive usage of opioids. Drug Alcohol Depend 2006;82:135-42.

20. Morgan SG, Raymond C, Mooney D, et al. The Canadian Rx Atlas, 2nd Edition. UBC Centre for Health Services and Policy Research. Vancouver, British Columbia, 2008.

21. Fischer B, Jones W, Krahn M, Rehm J. Differences and over-time changes in levels and trends of prescription opioid analgesic (POA) use dispensed from retail pharmacies in Canada, 2005 - 2010. Pharmacoepidemiol Drug Saf 2011;20:1269-77.

22. Health Canada. Canadian Alcohol and Drug Use Monitoring Survey 2008: Microdata User Guide. Health Canada. <http://prod. library.utoronto.ca/datalib/codebooks/cstdli/cadums/2008/cadumstechnical-guide-2008-final-eng.pdf> (Accessed 2009).

23. Health Canada. Canadian Alcohol and Drug Use Monitoring Survey 2010: Microdata user guide. Ottawa, Canada: Health Canada, 2011.

24. AIMS. L'Association de l'Industrie de la Recherche Marketing et Sociale. Quantitative Norms, 2010.

25. World Health Organization Collaborating Centre for Drug Statistics Methodology. ATC/DDD Index 2010. Norwegian Institute of Public Health. <www.whocc.no/atc_ddd_index/> (Accessed 2009).

26. Lumley T. Analysis of complex survey samples. J Stat Softw 2004;9:1-19.

27. R Development Core Team. R: A Language and Environment for Statistical Computing (version 2.13.0). Vienna, Austria: R Foundation for Statistical Computing, 2011.

28. International Narcotics Control Board. Narcotic drugs: Estimated world requirements for 2012, statistics for 2010. Vienna, Austria: International Narcotics Control Board, 2011.

29. Grant BF, Dawson DA. Age of onset of drug use and its association with DSM-IV drug abuse and dependence: Results from the National Longitudinal Alcohol Epidemiologic Survey. J Substance Abuse 1998;10:163-73.

30. DeWit DJ, Adlaf EM, Offord DR, Ogborne AC. Age at first alcohol use: A risk factor for the development of alcohol disorders. Am J Psychiatry 2000;157:745-50.

31. Kessler RC, Chiu WT, Demier O, Merikangas KR, Walters EE. Prevalence, severity, and comorbidity of 12 -month DSM-IV disorders in the National Comorbidity Survey Replication. Arch Gen Psychiatry 2005;62:617-27.
32. Tetrault JM, Desai RA, Becker WC, Fiellin DA, Concato J, Sullivan LE. Gender and non-medical use of prescription opioids: Results from a national US survey. Addiction 2008;103:258-68.

33. Reitsma ML, Tranmer JE, Buchanan DM, Vandenkerkhof EG. The prevalence of chronic pain and pain-related interference in the Canadian population from 1994-2008. Chronic Dis Can 2011;31:157-64.

34. Boulanger A, Clark AJ, Squire P, Cui E, Horbay GL. Chronic pain in Canada: Have we improved our management of chronic noncancer pain? Pain Res Manag 2007;12:39-47.

35. Lynch ME, Fischer B. Prescription opioid abuse: What is the real problem and how do we fix it? Can Fam Physician 2011;57:1241-2, e1403-5.

36. Chou R, Fanciullo GJ, Fine PG, et al. Clinical guidelines for the use of chronic opioid therapy in chronic noncancer pain. J Pain 2009;10:113-30.

37. Smith HS. Conventional practice for medical conditions for chronic opioid therapy. Pain Physician 2012;15:ES1-ES7.

38. Manchikanti L, Abdi S, Atluri S, et al; American Society of Interventional Pain Physicians. American Society of Interventional Pain Physicians (ASIPP) guidelines for responsible opioid prescribing in chronic non-cancer pain: Part 2 - guidance. Pain Physician 2012;15:S67-S116.

39. McCabe SE, Cranford JA, Boyd CJ, Teter CJ. Motives, diversion and routes of administration associated with nonmedical use of prescription opioids. Addict Behav 2007;32:562-75.

40. Fischer B, Rehm J. Nonmedical use of prescription opioids: Furthering a meaningful research agenda. J Pain 2008;9:490-3.

41. Paulozzi LJ, Xi Y. Recent changes in drug poisoning mortality in the United States by urban-rural status and by drug type. Pharmacoepidemiol Drug Safety 2008;17:997-1005.

42. Okie S. A flood of opioids, a rising tide of deaths. N Engl J Med 2010;18:21.

43. Fischer B, Jones W, Rehm J. High correlations between levels of consumption and mortality related to strong prescription opioid analgesics in British Columbia and Ontario, 2005 - 2009 Pharmacoepidemiol Drug Safety. In Press.

44. Shield K, Rehm J. Difficulties with telephone-based surveys on alcohol in high-income countries: The Canadian example. Int J Method Psych 2012;21:17-28.

45. Zhao J, Stockwell T, Macdonald S. Non-response bias in alcohol and drug population surveys. Drug Alcohol Rev 2009;28:648-57.

46. Sudman S, Bradburn N, Schwarz N. Thinking About Answers: The Application Of Cognitive Processes To Survey Methodology. San Francisco: Jossey-Bass, 1996. 


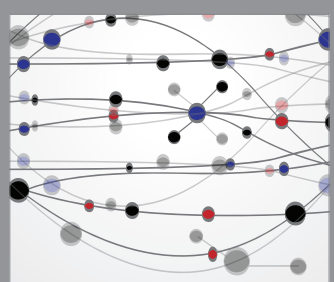

The Scientific World Journal
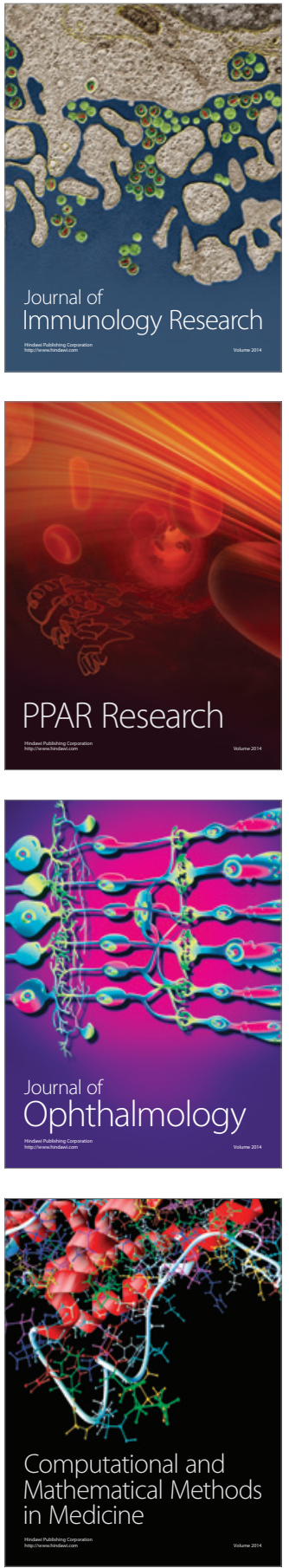

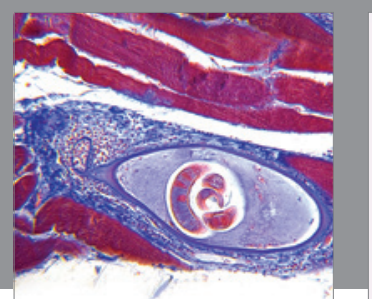

Gastroenterology Research and Practice

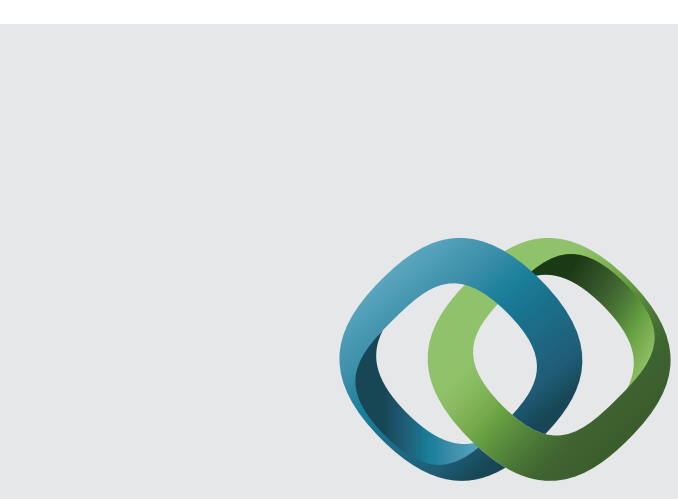

\section{Hindawi}

Submit your manuscripts at

http://www.hindawi.com
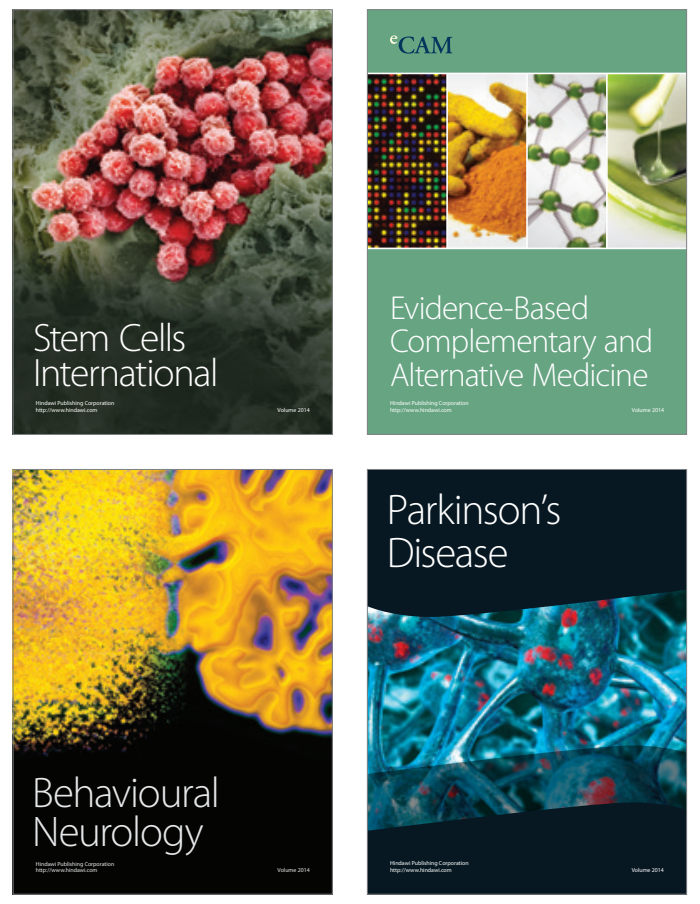
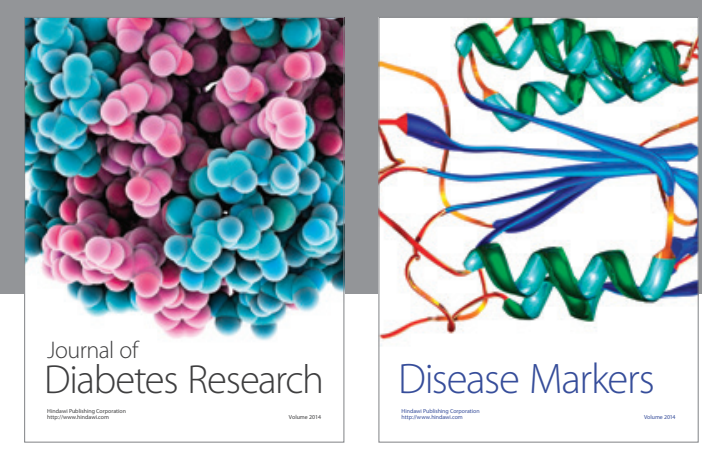

Disease Markers
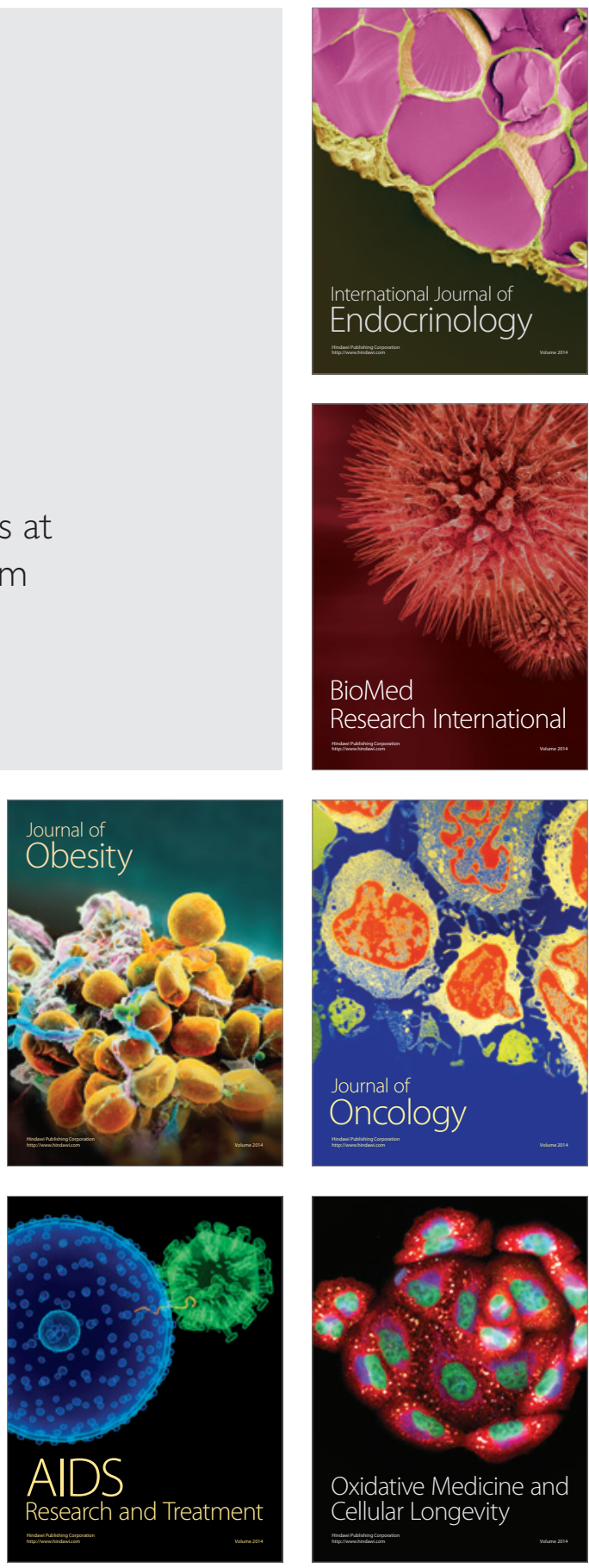